\title{
Unilateral hyperhidrosis associated with underlying intrathoracic neoplasia
}

\author{
D C LINDSAY, J G FREEMAN, C O RECORD
}

\section{From the Department of Medicine, Royal Victoria Infirmary, and University of Newcastle upon Tyne}

Intrathoracic neoplasia is notable for the many ways in which it may present. We would like to report two cases demonstrating a rare association between unilateral localised hyperhidrosis of the thoracic cage and underlying intrathoracic neoplasm.

\section{Case reports}

CASE 1

A 67 year old retired shotblaster complained of a $3 \mathrm{~kg}$ weight loss, mild dyspnoea, chest pain localised to the right costal margin, and profuse sweating localised to an area below the right scapula. He smoked 15 cigarettes per day. Examination confirmed a right sided localised band of sweating at the level of T6-9 posteriorly. Apart from minimal winging of the right scapula and some wasting of the right suprascapular muscles no abnormal neurological signs were detected. A chest radiograph showed a large right pleural effusion with collapse of the underlying lung. Analysis of the pleural fluid revealed no malignant cells or acid fast bacilli, but a pleural biopsy confirmed the presence of poorly differentiated carcinoma. A technetium radioisotope bone scan showed increased uptake in the anterior ends of the right 4th and 5th ribs. The abnormal sweating continued for a further six months but the patient's condition deteriorated with the development of intra-abdominal metastases and recurrent pleural effusions. He died at home; necropsy was not performed.

CASE 2

A 58 year old engineering foreman, known to have had Crohn's disease since 1974, complained of ache of two months' duration in the left side of his chest, malaise, and a weight loss of $12 \mathrm{~kg}$. He smoked 30 cigarettes a day and had had a brief exposure to asbestos. Examination revealed a large pleural effusion, which was confirmed on a chest radiograph. Analysis of the sputum and pleural fluid was unhelpful, as was a pleural biopsy. The appearances on a technetium radioisotope bone scan were normal. The dull ache over the left side of his chest worsened, and six months later he developed a localised band of profuse sweating at the level of T5-8 on the left side of his chest. There were no abnormal neurological signs. Repeat clinical and radiographic examination suggested a diagnosis of left pleural mesothelioma. The sweating continued until his death four months later. At necropsy the left lung was totally encased by the mesothelioma tissue, which had invaded the chest

Address for reprint requests: Dr CO Record, Department of Medicine, Royal Victoria Infirmary, Newcastle upon Tyne NE1 4LP.

Accepted 13 January 1986 wall. There were metastatic plaques in the right hemithorafy and abdominal cavity but no evidence of metastases in the brain or the spinal cord.

\section{Discussion}

The association of intrathoracic malignancy with sym $\stackrel{\infty}{=}$ pathetic neurological complications, especially Horner's syndrome, is well recognised, particularly in the case of tumours occurring at the thoracic inlet. Unilateral hyperhidrosis is an unusual phenomenon which has been reportef sporadically in association with various conditions, includ ${ }_{\sigma}$ ing intracranial malignancy, encephalitis, syringomyelia trauma, neuritis, cervical rib, osteoma of the dorsal spine, and chickenpox; in several cases no obvious underlyingo cause has been evident.

Unilateral hyperhidrosis associated with intrathoracif malignancy was first described in $1976^{12}$ and since then nine cases associated with primary tumours, including one meso thelioma, ${ }^{3}$ and one with metastases have been reported. I most cases the sweating has been localised to the same side as the tumour, although three cases of contralateral sweating have been reported. ${ }^{4-6}$

Direct invasion of a nerve by a tumour may produce pain and a disturbance of motor, sensory, or autonomic functionEccrine sweating is mediated by cholinergic sympathetif nerves arising from ganglia supplied by efferent fibres from T1-L2. Experimental studies have shown that there is cross innervation and that section of one or more anterior roots may cause no sweating loss; while electrical stimulation of single anterior root results in widespread sympatheticallo mediated effects over the distribution of at least five or si sympathetic ganglia. ${ }^{7}$ Two main mechanisms have been pose tulated for the phenomenon of unilateral hyperhidrosis Lesions of the preoptic area anterior to the hypothalamu@ may cause unilateral hyperhidrosis, ${ }^{5}$ although in our cases and several others there was no neurological or postmortento evidence of cerebral metastases. Irritation of nerves, as wa seen in the two cases associated with cervical ribs, may causer excitation of the autonomic efferent fibres; and in both cases excision of the cervical ribs abolished this. ${ }^{8}$ It has been pose tulated that direct infiltration of the sympathetic chain ma\% cause unilateral hyperhidrosis, which over a period of time has been observed to evolve into ipsilateral anhidrosis and Horner's syndrome. ${ }^{9}$ None the less it is unusual that the sympathetic stimulation should persist in some cases as long as six months, when operative and postmortem finding have confirmed extensive invasion and ablation of the sym pathetic chain by tumour tissue. ${ }^{69}$

Unilateral hyperhidrosis may remit spontaneously, as iR case 1; but in several cases it has been abolished by radiog therapy or surgery. ${ }^{1910}$ It is, however, usually a sign of advanced tumour spread and carries a poor prognosis. 


\section{References}

1 Walsh JC, Low PA, Allsop JL. Localised sympathetic overactivity: an uncommon complication of lung cancer. $J$ Neurol Neurosurg Psychiatry 1976;39:93-5.

2 Middleton WG. Bronchial carcinoma with pleural spread causing unilateral thoracic hyperhidrosis. Br Med J 1976;ii:563.

3 Pleet DL, Mandel S, Neilan B. Paroxysmal unilateral hyperhidrosis and malignant mesothelioma. Arch Neurol 1983; 40:256.

4 Wang YT, Singh D, Poh SC. Hemihyperhidrosis and intrathoracic malignancy. Singapore Med J 1981;22:86-8.
5 Poh SC. Bronchial carcinoma with hemilateral hyperhidrosis. Singapore Med J 1978;19:59-60.

6 McCoy BP. Apical pulmonary adenocarcinoma with contralateral hyperhidrosis. Arch Dermatol 1981;117:659-61.

7 Pool JL. Unilateral thoracic hyperhidrosis caused by osteoma of the tenth dorsal vertebra. $J$ Neurosurg 1956;11:111-5.

8 Telford ED. Cervical rib and hyperhidrosis. Br Med J 1942;ii:96.

9 Jegarajah S, Coutts II. Localised sympathetic overactivity: an unusual complication of bronchogenic carcinoma. $\mathrm{Br} J \mathrm{Dis}$ Chest 1977:71:300-2.

10 McEvoy M, Ryan M, Neale G, Pritchard J. Unilateral hyperhidrosis-an unusual presentation of bronchial carcinoma. Ir J Med Sci 1982;151:51-2.

\section{Book notices}

Current Pulmonology. Vol 6. Daniel H Simmons. (Pp 339; $£ 52.50$ hardback.) Chicago: Year Book Medical Publishers Inc, 1985. (Available in UK from Blackwell, Oxford.)

This book is the sixth in a series of annual reviews of topics in respiratory medicine. It is a selected collection of 12 topics and is not intended to be a comprehensive volume covering the whole of respiratory medicine. All the authors come from North America or Canada but are not all situated within the same institution and the editor has therefore drawn from the expertise of several centres. Inevitably the styles of authorship vary but this does not matter. The quality is not invariably high, but only one or two chapters disappoint: in the main the texts are detailed, well researched, well written, and informative. The sections on occupational lung disease, asthma, complications encountered in the immunocompromised host and pulmonary embolism are notable, while the contribution on the molecular biology of lung cancer gives the reader an exciting glimpse of the future of research into lung cancer and hints at the impact molecular biology will have on other lung diseases. The impact of this book is, however, diminished by already being two years out of date. No reference is more recent than 1983 and, although this most likely reflects the interval between the preparation of manuscripts and their publication, it seems a pity that a book entitled Current Pulmonology is subject to such a delay. I believe that a two year interlude is too long and may make the discriminating reader look elsewhere. Furthermore, the entirely transatlantic authorship has resulted in a very heavy bias in the references. This is apparent, for example, in the poor review of inhaled corticosteroids in chapter 11 and the skimpy treatment of anticholinergic treatment and nebuliser treatment in chapters 3 and 11 . This text can be recommended to anyone wishing an overview of the subjects covered, provided that they do not expect detail on the more recent developments, for which they will have to refer to contemporary publications.

$\mathrm{R}$ du B

Environmental Health Criteria 55: Ethylene Oxide. Published under joint sponsorship of the UN Environment Programme, the International Labour Organisation, and WHO. (Pp 79; 9 Sw Fr.) Geneva: World Health Organisation, 1985.

This booklet is the latest in the "Environmental Health" series published by the World Health Organisation and summarises available toxicological information relating to human and animal exposure to ethylene oxide. The recorded risks to individuals who work with ethylene oxide or who come into contact with equipment that has been sterilised with ethylene oxide appear to be very slight indeed. The booklet could nevertheless be a useful source of reference to any clinician asked to comment on possible harmful effects of exposure to the agent.

\section{Notices}

Scadding-Morriston Davies joint fellowship in respiratory medicine 1987

This fellowship is available to support visits to medical centres in the United Kingdom or abroad for the purpose of undertaking studies related to respiratory medicine. Medical graduates practising in the UK, including consultants, irrespective of the number of years in that grade, may apply. Applicants should submit a curriculum vitae together with a detailed account of the duration and nature of the proposed work and the centres to be visited, confirming that these have agreed to provide the facilities required, and giving the sum of money needed for travel and subsistence. A sum of up to $£ 10000$ may be awarded to a successful applicant, or the sum may be divided to support two or more applicants. Applications should be sent by 31 January 1987 to Dr KM Citron, (secretary for the fellowships), Brompton Hospital, London SW3 6HP

\section{World Congress on Oxygen Therapy and Home Care}

A world congress on oxygen therapy and home care will be held at the Marriott Hotel, City Center, Denver, on 19-21 February 1987. The congress is being held under the auspices of the Webb-Waring Lung Institute and the American Association for Respiratory Care. The date for abstracts has already passed. Those interested in attending this meeting are invited to write to the Congress Secretariat at WebbWaring Lung Institute, 4200 E Ninth Avenue Box C-321, Denver Colorado 80262, USA. 